\title{
Canadian Studies in Population
}

\author{
Official Journal of the \\ Canadian Population Society
}

\section{Editor}

Frank Trovato, University of Alberta

Assistant to the Editor

Wendy Aujla, University of Alberta

\author{
Special Issue
}

\section{Global and Canadian Population and Beyond}

Guest Editor

Susan A. McDaniel, Prentice Institute for Global

Population and Economy, University of Lethbridge

Vol. 41, No. 3-4 (Fall/Winter) 2014 


\section{Population Research Laboratory, University of Alberta}

(C) 2014 by the Canadian Population Society and the Population

Research Laboratory, University of Alberta, Edmonton

All rights reserved. Published 2014

ISSN 0380-1489

Frank Trovato, Editor

Wendy Aujla, Assistant Editor

Canadian Studies in Population (CSP) is indexed in the Web of Science, the largest and most comprehensive citation index available. All articles published in CSP since 2009 are indexed and abstracted in the Social Sciences Citation Index, Journal Citation Reports/Social Sciences Edition, and in Current Contents/Social and Behavioral Sciences.

The Canadian Studies of Population journal are available online at http://web.uvic.ca/ canpop/ journal/.

Canadian Studies in Population was founded by Dr. P. Krishnan, Professor Emeritus at the University of Alberta, and is published with the financial support of the Society of Edmonton Demographers, Population Research Laboratory, Canadian Population Society, and the Department of Sociology, University of Alberta.

Funding for Canadian Studies in Population is provided by the Social Sciences and Humanities Research Council of Canada (SSHRC). 


\section{Contents}

1-5 Introduction: Global and Canadian population and beyond

Susan A. McDaniel

6-21 At the crossroads: Geography, gender and occupational sector in employment-related geographical mobility

Michael Haan, Deatra Walsh, and Barbara Neis

22-48 Geographic structure of the migrant labour market in China: A case study of four city-regions in Fujian

Li Yu, Wei Xu, Yu Zhu, and Liyue Lin

49-87 Assessing sex differentials in under-five mortality in sub-Saharan Africa: A cross-national comparative analysis

Adébiyi Germain Boco

88-104 Income inequality, status seeking, and savings rates in Canada

Alexander Darku

105-16 Wage differentials of males and females in same-sex and different-sex couples in Canada, 2006-2010

Richard E. Mueller

117-34 Complicating food security: Definitions, discourses, commitments

William Ramp

135 Book reviews 
Canadian Studies in Population 41, no. 3-4 (Fall/Winter 2014): Prentice Institute Special Issue 